\title{
Thermoluminescent dosimetry of panoramic radiography
}

\author{
Yo-Seob Seo ${ }^{1 *}$ and Sun-Kyoung $\mathrm{Yu}^{2}$ \\ ${ }^{1}$ Associate Professor, Deptartment of Oral and Maxillofacial Radiology, College of Dentistry, Chosun University, Gwangju, Republic of Korea \\ ${ }^{2}$ Associate Professor, Department of Oral Anatomy, College of Dentistry, Chosun University, Gwangju, Republic of Korea
}

This study aims to calibrate a thermoluminescence dosimeter (TLD) using a diagnostic radiation device and evaluate the dose of panoramic radiography. TLD-100s were calibrated using a solid-state dosimeter (Unfors Mult-O-Meter 512L; Unfors Instruments, Billdal, Sweden) and a diagnostic radiation device (HDT-500R; Hyun Dai Medical X-ray Co., Paju, Korea). Forty eight TLDs were placed in 24 sites of a head and neck phantom of a male (ART-210; Radiology Support Devices Inc., Long Beach, CA, USA), and panoramic radiation was performed under exposure parameters of $70 \mathrm{kVp}$ and $10 \mathrm{~mA}$ using a ProMax (Planmeca, Helsinki, Finland). Using the International Commission on Radiological Protection (ICRP) 2007 recommendation, the effective dose of panoramic radiography was calculated from the absorbed doses of the tissues of the 24 TLD sites in a head and neck phantom. The absorbed dose of the TLD site was higher in the parotid gland (right: $1854.4 \mu \mathrm{Gy}$, left: $1788.9 \mu \mathrm{Gy})$ and lower in the calvarium anterior (3.8 $\mu \mathrm{Gy})$. The effective dose was calculated at $28.4 \mu \mathrm{Sv}$. The cancer and heritable risks were $1.56 \times 10^{-6}$ and $5.67 \times 10^{-8}$, respectively. The TLD was calibrated using a diagnostic radiographic device, and the panoramic radiographic dose was evaluated. The findings of this study could be helpful in future dose studies.

Key Words: Radiation Dosage; Radiography, Dental; Radiography, Panoramic

(c) This is an open-access article distributed under the terms of the Creative Commons Attribution Non-Commercial License (http://creativecommons.org/licenses/by-nc/4.0) which permits unrestricted noncommercial use, distribution, and reproduction in any medium, provided the original work is properly cited.

\section{Introduction}

Radiation is commonly known to be harmful. The effects of radiation are classified as deterministic and stochastic; deterministic effects are evaluated as equivalent doses $\left(\mathrm{H}_{\mathrm{T}}\right)$ and stochastic effects as effective doses (E) [1,2]. In 1990, 2005, and 2007, the International Commission on Radiological Protection (ICRP) published the tissue weighting factors $\left(\mathrm{W}_{\mathrm{T}}\right)$ required to calculate effective dose [3-5]. The tissue weighting factors for the ICRP 1990 recommendations are based on mortality of cancer, whereas those for
ICRP 2007 recommendations are based on cancer incidence. Notably, effective dose may vary from $23 \%$ to $224 \%$ when tissue weighting factors of the ICRP 1990 and 2007 recommendations are applied [6].

Since effective dose presents radiation hazards to the entire body, the risks of different radiographs could be directly compared. However, effective dose do not reflect individual characteristics such as age, sex, and genetic radioactivity [7].

Effective dose of panoramic radiography ranges from 3.85 to $39 \mu \mathrm{Sv}$, which indicates a significant variation [8,9]. Lud-

Received February 18, 2021; Revised March 5, 2021; Accepted March 5, 2021

${ }^{\star}$ Corresponding author: Yo-Seob Seo, Deptartment of Oral and Maxillofacial Radiology, College of Dentistry, Chosun University, 303 Pilmundaero, Dong-gu, Gwangju 61452, Republic of Korea.

Tel: +82-62-220-3887, Fax: +82-62-224-6269, E-mail: moresys@chosun.ac.kr

Copyright $\odot$ 2021, Oral Biology Research Institute 
low and Ivanovic [6] reported that the value of the dosimeter could vary by approximately $23 \%$, depending on the collimator adjustment, unit calibration, and phantom position in the unit. Lee et al. [8] reported that effective dose could vary depending on the gender of the phantom, the number and location of the thermoluminescent dosimeter (TLD) used, and the exposure conditions, even for a similar panoramic device.

Various methods using TLD, optically stimulated luminescence dosimeter, solid-state dosimeter, dose area product, and ionization chamber can be used for dose studies $[1,7,10]$. The most widely used method for measuring doses by placing TLDs into anthropomorphic phantoms requires significant time and effort, but it has been used as a basis for comparison in the study of doses in other methods [6,7].

In dosimetry using TLD, calibration of TLD is crucial for obtaining a conversion factor between the response of the dosimeter and the absorbed dose $\left(D_{T}\right)$, as well as for improving the homogeneity of the TLD response. Radiation sources using radioactive isotopes, such as Co-60 and Cs137, have been used to irradiate TLDs. Using X-rays as a radiation source is a medical linear accelerator, and the use of diagnostic radiation devices has rarely been reported [11-13].

This study aims to calibrate the TLD using a diagnostic radiation device and evaluate the dose of panoramic radiography.

\section{Materials and Methods}

\section{Thermoluminescence dosimeter calibration}

A diagnostic radiation device (HDT-500R; Hyun Dai Medical X-ray Co., Paju, Korea) was used to expose the TLDs to radiation. The focus of the HDT-500R was adjusted, and one of the quartiles based on the central guide line within the field of view of the HDT-500R was selected (Fig. 1A).

A solid-state dosimeter (Unfors Mult-O-Meter 512L; Unfors Instruments, Billdal, Sweden) was calibrated by the Korea Atomic Energy Research Institute and used to select the irradiation area where the dose decreased or increased relatively evenly between horizontal and vertical lines within the selected quartile.

The irradiation area was $7 \mathrm{~mm}$ from the centerline of the horizontal and vertical lines and was selected for the TLD phantom $104 \mathrm{~mm}$ wide and $88 \mathrm{~mm}$ long. The TLD phantom with 108 holes for a TLD was obtained using polymethylmethacrylate, which has no significant difference in dose calculation [10].

The exposure parameters of the HDT-500R (46.1 kVp, $200 \mathrm{~mA}$, and $0.2 \mathrm{~s}$ ) were set. Doses in the irradiation area were measured using a solid-state dosimeter at nine sites: lower right (area 1); lower middle (area 2); lower left (area 3); middle right (area 4); middle (area 5); middle left (area 6); upper right (area 7); upper middle (area 8); and upper left (area 9) (Fig. 1B).
A

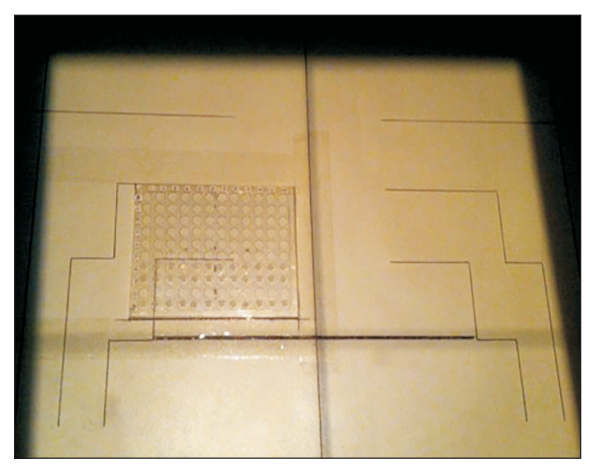

B

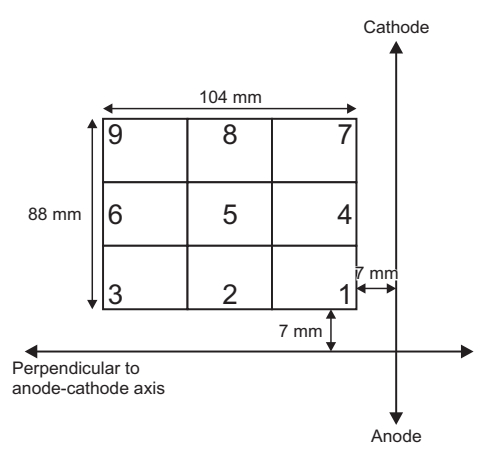

C

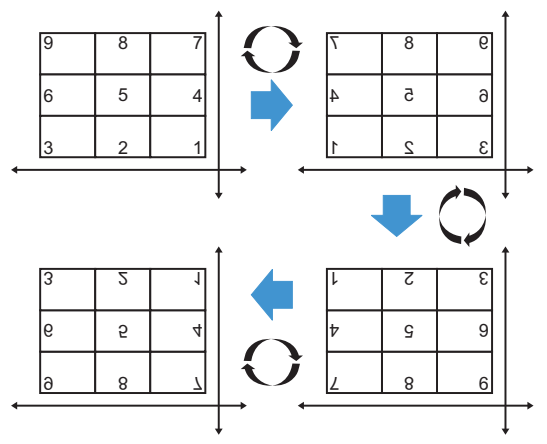

Fig. 1. Irradiation area and irradiation method for calibrating TLD. (A) TLD phantom was located in the irradiation area within the quartile of the field of view. (B) In the irradiation area, doses were measured using a solid-state dosimeter at nine sites: lower right (area 1); lower middle (area 2); lower left (area 3); middle right (area 4); middle (area 5); middle left (area 6); upper right (area 7); upper middle (area 8); upper left (area 9). (C) The TLD phantom with TLDs in the irradiation area was exposed to radiation in the normal position and by flipping horizontally, vertically, and horizontally. TLD, thermoluminescence dosimeter. 
The TLD phantom with TLDs in the irradiation area was exposed to radiation in the normal position by flipping horizontally, vertically, and horizontally (Fig. 1C).

Nine sites in the irradiation area were divided into four groups. As shown in Fig. 1, areas 1, 3, 7 and 9 (A group) are exposed in four corner positions successively; areas 2 and 8 (B group) are exposed successively; areas 4 and 6 (C group) are exposed in the same position successively; area 5 (D group) is exposed in the same position four times.

The sum dose was obtained by grouping, and its mean was the reference dose for calibrating the TLD. TLDs with an error correction coefficient between 0.77 and 1.43 were selected and used.

Harshaw TLD-100 (Thermo Electron Co., Oakwood Village, $\mathrm{OH}, \mathrm{USA}$ ) was used after annealing at $400^{\circ} \mathrm{C}$ for 1 hours. The energy of the TLD was measured using a Harshaw 3500 (Harshaw/Bicron, Solon, OH, USA).

\section{Dosimetry of panoramic radiography}

A ProMax (Planmeca, Helsinki, Finland) and the head and neck phantom of a male (ART-210; Radiology Support Devices Inc., Long Beach, CA, USA) were used to measure the absorbed dose of panoramic radiation (Fig. 2). And forty eight TLDs were placed in 24 sites of the head and neck phantom (Table 1).

Panoramic radiography was performed 10 times under

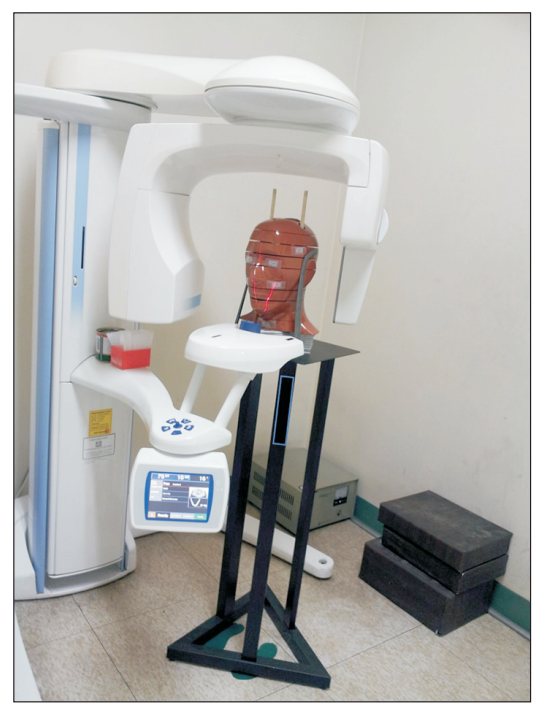

Fig. 2. Head and neck phantom. the exposure parameters of $70 \mathrm{kVp}$ and $10 \mathrm{~mA}$, which are the normal settings for adult patients. Additionally, the background radiation was measured using two TLDs.

After reading the TLD and subtracting the average of the background radiation from the average absorbed dose of each site, the absorbed dose of each site was obtained by converting it to a single exposure. The absorbed dose of the tissue/organ for calculating effective dose was calculated by averaging the selected sites among the 24 TLD sites (Table 2). The bone surface dose is derived from the bone dose [14].

The equivalent dose is the absorbed dose multiplied by the radiation weighting factor, and $\mathrm{X}$-rays have a radiation weighting factor of 1 . Therefore, the equivalent dose was equal to the absorbed dose. Moreover, effective dose was calculated as the sum of equivalent dose multiplied by the fraction ratio of tissue/organ exposed to radiation (fraction irradiated) and tissue weighting factors, using the following

Table 1. Location of TLDs and absorbed doses in head and neck phantom

\begin{tabular}{lcc}
\hline \multicolumn{1}{c}{$\begin{array}{c}\text { Phantom location } \\
\text { (phantom level) }\end{array}$} & TLD ID & $\begin{array}{c}\text { Absorbed dose } \\
(\mu \mathrm{Gy})\end{array}$ \\
\hline Calvarium anterior (2) & 1 & 3.8 \\
Calvarium left (2) & 2 & 16.1 \\
Calvarium posterior (2) & 3 & 18.4 \\
Mid brain (2) & 4 & 21.8 \\
Pituitary (3) & 5 & 28.2 \\
Right lens of eye (3) & 6 & 5.6 \\
Left lens of eye (3) & 7 & 9.4 \\
Right orbit (4) & 8 & 13.0 \\
Left orbit (4) & 9 & 14.4 \\
Right cheek (5) & 10 & 29.2 \\
Right parotid (6) & 11 & 1854.4 \\
Left parotid (6) & 12 & 1788.9 \\
Right ramus (6) & 13 & 518.2 \\
Left ramus (6) & 14 & 615.9 \\
Center C spine (6) & 15 & 566.3 \\
Left back of neck (7) & 16 & 339.3 \\
Right mandible body (7) & 17 & 117.7 \\
Left mandible body (7) & 18 & 157.6 \\
Right submandibular gland (7) & 19 & 437.5 \\
Left submandibular gland (7) & 20 & 409.5 \\
Center sublingual gland (7) & 21 & 213.0 \\
Midline thyroid (9) & 22 & 70.7 \\
Thyroid surface-middle (9) & 23 & 36.5 \\
Esophagus (9) & 24 & 102.7 \\
\hline
\end{tabular}

TLD, thermoluminescence dosimeter. 
Table 2. TLDs used to calculate the absorbed dose of tissue, fraction ratio of tissue/organ exposed to radiation (fraction irradiated), tissue weighting factors $\left(\mathrm{W}_{\mathrm{T}}\right)$, and equivalent dose $\left(\mathrm{H}_{\mathrm{T}}\right)$ used to calculate the effective dose

\begin{tabular}{|c|c|c|c|c|c|}
\hline Tissue/organ & TLD ID & Fraction irradiated & $\mathbf{W}_{\mathrm{T}}$ & $\mathbf{H}_{\mathrm{T}}$ & Effective dose calculation \\
\hline Bone marrow & & $16.5 \%$ & 0.12 & & 3.0 \\
\hline Mandible & $13,14,17,18$ & $1.3 \%$ & & 352.3 & \\
\hline Calvaria & $1,2,3$ & $11.8 \%$ & & 12.7 & \\
\hline Cervical spine & 15 & $3.4 \%$ & & 566.3 & \\
\hline Thyroid & 22,23 & $100.0 \%$ & 0.04 & 53.6 & 2.1 \\
\hline Esophagus & 24 & $10.0 \%$ & 0.04 & 102.7 & 0.4 \\
\hline Skin & $6,7,10,16$ & $11.0 \%$ & 0.01 & 95.9 & 0.1 \\
\hline Bone surface $^{a}$ & & $16.5 \%$ & 0.01 & & 1.0 \\
\hline Mandible & $13,14,17,18$ & $1.3 \%$ & & 1429.3 & \\
\hline Calvaria & $1,2,3$ & $11.8 \%$ & & 51.7 & \\
\hline Cervical spine & 15 & $3.4 \%$ & & 2297.1 & \\
\hline Salivary glands & & $100.0 \%$ & 0.01 & & 8.2 \\
\hline Parotid & 11,12 & & & 1821.6 & \\
\hline Submandibular & 19,20 & & & 423.5 & \\
\hline sub-lingual & 21 & & & 213.0 & \\
\hline Brain & 4,5 & $100.0 \%$ & 0.01 & 25.0 & 0.2 \\
\hline Remainder & & & 0.12 & & 13.2 \\
\hline Lymphatic nodes & $11-15,17-22,24$ & $40.0 \%$ & & 571.0 & \\
\hline Muscle & $11-15,17-22,24$ & $5.0 \%$ & & 571.0 & \\
\hline Extrathoracic airway & $8,9,11-15,17-22,24$ & $100.0 \%$ & & 491.4 & \\
\hline Oral mucosa & $11-14,17-21$ & $100.0 \%$ & & 679.2 & \\
\hline \multicolumn{5}{|c|}{ Effective dose } & 28.4 \\
\hline
\end{tabular}

TLD, thermoluminescence dosimeter.

${ }^{a}$ Bone surface dose=bone marrow dose $\times$ bone/muscle mass energy absorption coefficient ratio (MEACR). MEACR $=-0.0618 \times 2 / 3 \mathrm{kV}$ peak +6.9406 using data taken from National Bureau of Standards handbook no. 85 [14].

Table 3. Tissue weighting factors $\left(\mathrm{W}_{\mathrm{T}}\right)$ for calculation of effective dose ICRP $2007 \mathrm{draft}$ recommendations

\begin{tabular}{lcc}
\multicolumn{1}{c}{ Tissue/organ } & $\mathbf{W}_{\mathrm{T}}$ & $\Sigma \mathbf{W T}$ \\
\hline Bone marrow, breast, colon, lung, stomach, Remainder tissues ${ }^{\mathrm{a}}$ & 0.12 & $0.12 \times 6=0.72$ \\
Gonads & 0.08 & $0.08 \times 1=0.08$ \\
Bladder, esophagus, liver, thyroid & 0.04 & $0.04 \times 4=0.16$ \\
Bone surface, brain, salivary glands, skin & 0.01 & $0.01 \times 4=0.04$ \\
Sum & & 1.00 \\
\hline
\end{tabular}

ICRP, International Commission on Radiological Protection.

aAdrenals, extrathoracic region, gall bladder, heart, kidneys, lymphatic nodes, muscle, oral mucosa, pancreas, prostate, small intestine, spleen, thymus, and uterus/cervix.

formula: $\mathrm{E}=\sum \mathrm{H}_{\mathrm{T}} \times \mathrm{W}_{\mathrm{T}}$ (Tables 2 and 3). The tissue weighting factors were applied by ICRP 2007 [4].

The cancer and heritable risks were calculated by multiplying effective dose by the detriment adjusted nominal risk coefficients for cancer $\left(5.5 \times 10^{-2} / \mathrm{Sv}\right)$ and heritable effects $\left(0.2 \times 10^{-2} / \mathrm{Sv}\right)$.

\section{Results}

In the irradiation area, the dose measured by the solidstate dosimeter was higher in area $7(464.2 \mu \mathrm{Gy})$ and lower in area $3(402.9 \mu \mathrm{Gy})$. The average of the doses in each area was $433.5 \mu \mathrm{Gy}$, with a standard deviation of 20.4 and a coefficient variation of 4.7. The dose in the irradiation area increased as it moved upward from the center line and decreased as it moved to the left (Table 4). 
Table 4. Doses of irradiation area

\begin{tabular}{cccccc}
\hline & Area & & & \multicolumn{2}{c}{ Dose $(\mu \mathrm{Gy})$} \\
\hline 9 & 8 & 7 & 434.7 & 453.5 & 464.2 \\
6 & 5 & 4 & 410.9 & 435.7 & 449.7 \\
3 & 2 & 1 & 402.9 & 417.2 & 432.5 \\
& Average & & & 43.5 & 20.4 \\
& Stdev & & & 4.7 \\
\hline
\end{tabular}

Stdev, standard deviation; CV, coefficient of variation.

For visibility, it is arranged in order of exposure location, not number order.

The sum dose by group was higher in group D (1742.6 $\mu \mathrm{Gy})$ and lower in group C (1721.2 $\mu \mathrm{Gy})$. The average sum dose by group was $1734.9 \mu \mathrm{Gy}$, with a standard deviation of 9.8 and a coefficient variation of 0.6 (Table 5). The reference dose for calibrating the TLD was $1734.9 \mu \mathrm{Gy}$.

The absorbed dose of the TLD site was higher in the parotid gland (right: $1854.4 \mu \mathrm{Gy}$, left: $1788.9 \mu \mathrm{Gy}$ ), followed by that in the left ramus $(615.9 \mu \mathrm{Gy})$, cervical vertebrae $(566.3 \mu \mathrm{Gy})$, and lower in the calvarium anterior $(3.8 \mu \mathrm{Gy})$ (Table 1).

The equivalent dose of the tissue/organ required to calculate effective dose is shown in Table 2.

The effective dose was calculated at $28.4 \mu \mathrm{Sv}$. The cancer and heritable risks were $1.56 \times 10^{-6}$ and $5.67 \times 10^{-8}$, respectively.

\section{Discussion}

TLD-100 is widely used for dose research because of its excellent physical characteristics such as homogeneity, reproducibility, and linearity, although it has some disadvantages such as reading once, being sensitive to light, and being affected by moisture or dust $[15,16]$. For TLD calibration, Co-60, Cs-137, Ir-192, and medical linear accelerator may be used to irradiate the reference dose, and the actual radiation dose may differ from the planned doses by $0-6 \%$ depending on the irradiation method [11-13,16-18]. Because the diagnostic radiation device cannot irradiate the planned dose, the dose measured using a solid-state dosimeter was the reference dose. Additionally, to reduce the difference in dose distribution, it was irradiated repeatedly by flipping the TLD phantom horizontally and vertically (Fig. 1). Methods for irradiating TLDs uniformly using diagnostic
Table 5. Sum doses by exposure group

\begin{tabular}{clcc}
\hline Group & & Area & Sum dose $(\mu \mathrm{Gy})$ \\
\hline A & & $1,3,7,9$ & 1734.2 \\
B & & 2,8 & 1741.4 \\
C & & 4,6 & 1721.2 \\
D & & 5 & 1742.6 \\
& Average & & 1734.9 \\
& Stdev & & 9.8 \\
& CV & & 0.6 \\
\hline
\end{tabular}

Stdev, standard deviation; CV, coefficient of variation.

radiation devices were devised and studied, but uncertainty verification was not performed. Considering this, follow-up research will be needed.

Analyzing the absorbed doses of the TLDs located on the face indicates that the dose decreases as it moves away from the central ray in order of cheek $(29.2 \mu \mathrm{Gy})$ at phantom level 5, orbit (right $13.0 \mu \mathrm{Gy}$, left $14.4 \mu \mathrm{Gy}$ ) at phantom level 4 , lens of the eye (right $5.6 \mu \mathrm{Gy}$, left $9.4 \mu \mathrm{Gy}$ ) at phantom level 3 , and calvarium anterior $(3.8 \mu \mathrm{Gy})$. However, the difference in the dose of parotid gland (right 1854.4 $\mu \mathrm{Gy}$, left $1788.9 \mu \mathrm{Gy}$ ), ramus (right $518.2 \mu \mathrm{Gy}$, left 615.9 $\mu \mathrm{Gy})$, and center of $\mathrm{C}$-spine $(566.3 \mu \mathrm{Gy})$ at phantom level 6 indicates that not all areas are irradiated equally during panoramic radiography (Table 1 ). This is because the areas where the ghost and double images can be formed are irradiated several times, and an understanding of panoramic geometry is required to analyze the absorbed dose of panoramic radiography.

Ludlow and Ivanovic [6] calculated the skin and lymph nodes of the head and neck as 5\%. However, in this study, the head and neck skin was applied as $9 \%$ by rule of nine at burn, and lymph node as $37.5 \%$. This is because 300 of the 800 lymph nodes were located in the neck [19,20]. 
The effective dose in this study was $28.4 \mu \mathrm{Sv}$, which is different from the $24.3 \mu \mathrm{Sv}$ obtained using the same equipment by Ludlow et al. [21]. The difference could be attributed to the differences in exposure parameters, the position of the phantom, the position of the TLDs, and the difference in the fraction ratio of the tissue/organ applied.

In this study, the sum of tissue weighting factors used in calculating the dose was 0.36 . Tissue/organ equivalent to 0.64 is missing (Table 2). The dose will be further reduced if the measuring area is reduced. Lee et al. [8] reported that effective dose of the entire body, including the head and neck, was higher than that calculated by the head and neck alone in a study using an entire body phantom. Although dental radiation is used mainly in the head and neck areas, an entire body phantom is suitable. In addition, dentists should be able to understand dose concepts and analyze dose-related reports because they select radiation equipment and determine how and how many radiographs should be taken.

Some researchers have calculated equivalent doses by multiplying the fraction ratio of the tissue $[6,8]$. Equivalent dose is smaller when only a fraction of the tissue is exposed to radiation (such as bone marrow, skin, and lymph nodes). Because equivalent doses are doses to deterministic effects, doses from exposed areas should be applied as is.

The application of fraction ratios to the effective dose may also be controversial. This is because it is difficult to expect the effects of radiation-induced cancer on areas other than the fingers when radiation irradiates the fingers. In addition, the units of equivalent dose and effective dose are Sv, thus causing confusion. The concepts and methods for obtaining doses need to be studied and developed further.

Therefore, there is a limit to evaluating the harmful effects of radiography using only effective dose. Absorbed doses from the TLD location should be revealed to re-interpret the results of the study by assessing the adequacy of the study and applying dose-producing methods that may vary depending on time.

Because the method for radiation risk assessment is not perfect, dose studies should continue to develop new concepts of radiation. Further, new equipment should be introduced for dose studies, and the possibility of changes in how the existing equipment are used should be investigated. The findings of this study could be helpful in future dose studies.

\section{Acknowledgements}

This study was supported by research funds from Education and Cultural Foundation of College of Dentistry, Chosun University, 2019.

\section{Conflicts of Interest}

The authors declare that they have no competing interests.

\section{ORCID}

\author{
Yo-Seob Seo \\ https://orcid.org/0000-0003-1804-5648 \\ Sun-Kyoung Yu \\ https://orcid.org/0000-0003-0801-1663
}

\section{References}

1. Korean Council of professors of oral and maxillofacial radiology. Oral and maxillofacial radiology. 5th ed. Seoul: Narae publishing Inc.; 2015.

2. Mallya SM, Lam EWN. White and Pharoah's oral radiology: principles and interpretation. 8th ed. St. Louis: Elsevier; 2019.

3. International Commission on Radiological Protection. 1990 recommendations of the International Commission on Radiological Protection. Ann ICRP 1991;21:1-201.

4. International Commission on Radiological Protection. ICRP publication 103: recommendations of the ICRP. Radiat Prot Dosim 2008;129:500-507. doi: 10.1093/rpd/ncn187.

5. Ludlow JB, Davies-Ludlow LE, Brooks SL, Howerton WB. Dosimetry of 3 CBCT devices for oral and maxillofacial radiology: CB Mercuray, NewTom 3G and i-CAT. Dentomaxillofac Radiol 2006;35:219-226. doi: 10.1259/ dmfr/14340323.

6. Ludlow JB, Ivanovic M. Comparative dosimetry of dental CBCT devices and 64-slice CT for oral and maxillofacial radiology. Oral Surg Oral Med Oral Pathol Oral Radiol Endod 2008;106:106-114. doi: 10.1016/j.tripleo.2008.03.018.

7. Kim EK, Han WJ, Choi JW, Battulga B. Estimation of the effective dose of dental cone-beam computed tomography using personal computer-based Monte Carlo software. Imaging Sci Dent 2018;48:21-30. doi: 10.5624/ 
isd.2018.48.1.21.

8. Lee GS, Kim JS, Seo YS, Kim JD. Effective dose from direct and indirect digital panoramic units. Imaging Sci Dent 2013;43:77-84. doi: 10.5624/isd.2013.43.2.77.

9. Li G. Patient radiation dose and protection from conebeam computed tomography. Imaging Sci Dent 2013;43:63-69. doi: 10.5624/isd.2013.43.2.63.

10. Endo A, Katoh T, Kobayashi I, Joshi R, Sur J, Okano T. Characterization of optically stimulated luminescence dosemeters to measure organ doses in diagnostic radiology. Dentomaxillofac Radiol 2012;41:211-216. doi: 10.1259/ dmfr/98708146.

11. Brady SL, Toncheva G, Dewhirst MW, Yoshizumi TT. Characterization of a 137Cs irradiator from a new perspective with modern dosimetric tools. Health Phys 2009;97:195205. doi: 10.1097/HP.0b013e3181a9bd42.

12. Moafi M, Geraily G, Shirazi AR. Comparison of thermoluminescent dosimeter calibration irradiated in gamma knife and 60Co instruments. J Cancer Res Ther 2019;15 Suppl:S123-S126. doi: 10.4103/jcrt.JCRT_1200_16.

13. Singh R, Oinam AS, Trivedi G, Kainth HS, Shahi JS, Singh B, Kapoor R. A comparative study for surface dose evaluation in conventional treatment of carcinoma breast patients irradiated with Co-60 and 6 MV radiation beam. J Cancer Res Ther 2019;15:1035-1041. doi: 10.4103/jcrt. JCRT_789_17.

14. International Commission on Radiological Units and Measurements, United States. National Bureau of Standards.
Physical aspects of irradiation: recommendations of the International Commission on Radiological Units and Measurements (ICRU). Report 10b 1962. Washington DC: US Government Printing Office; 1964.

15. Moor DM, Horspool B, Stokes RP. Performance of the Harshaw DXT-RAD (TLD-100) dosemeter. Radiat Meas 2008;43:533-537. doi: 10.1016/j.radmeas.2007.11.035.

16. Haworth A, Butler DJ, Wilfert L, Ebert MA, Todd SP, Hayton AJ, Kron T. Comparison of TLD calibration methods for 192Ir dosimetry. J Appl Clin Med Phys 2013;14:258-272. doi: 10.1120/jacmp.v14i1.4037.

17. Sadeghi M, Sina S, Faghihi R. Investigation of LiF, Mg and Ti (TLD-100) reproducibility. J Biomed Phys Eng 2015;5:217222.

18. Rijken JD, Harris-Phillips W, Lawson JM. Calculation of the TLD700:LiF energy response from Ir-192 using novel Monte Carlo and empirical methods. Australas Phys Eng Sci Med 2015;38:129-138. doi: 10.1007/s13246-015-0332-y.

19. Senarath-Yapa K, Enoch S. Management of burns in the community. Wounds UK 2009;5:38-48.

20. Som PM. Lymph nodes of the neck. Radiology 1987;165: 593-600. doi: 10.1148/radiology.165.3.3317494.

21. Ludlow JB, Davies-Ludlow LE, White SC. Patient risk related to common dental radiographic examinations: the impact of 2007 International Commission on Radiological Protection recommendations regarding dose calculation. J Am Dent Assoc 2008;139:1237-1243. doi: 10.14219/jada. archive.2008.0339. 